\title{
Assessment of the Reliability of Different Components of Fuel Measurement Systems Used in Angola
}

\author{
Henrique Vieira Afonso and José Sebastião Dunge
}

\author{
${ }^{a}$ Mecanical Engineering Department, Engineering Faculty of Agostinho Neto University (UAN), Luanda, Angola, Renewable Energy, Avenida 21 \\ de Janeiro, Luanda, Angola.

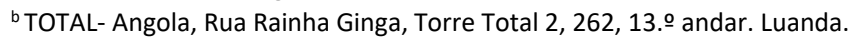

\section{ARTICLE INFO}

\section{Keywords:}

System,

measurement, fuel

reliability;

Maintenance;

Statistics, Analysis,

Components

\begin{abstract}
The present work aims to assess the reliability of the different fuel measurement systems used at SNLD filling stations. As objectives, it is intended to propose a methodology for selecting the types and models of pumps to be used and when to replace them. The assessment of the risks in the replacement of a pump and the impact on the environment will also be examined. Although the discussion on pumps is not new in Angola, there are no published records on this subject, particularly in the selection of types and models of systems to be used and when to replace, using the different scientific tools. For the analysis of these equipments and their reliability, weibull distribution, ANOVA analysis and computational tools of probability and statistics with excel were used. The analysis by these two methods made it possible to certify the results obtained. A benchmarking was carried out at the filling stations of SNLD, Pumangol and Sonagalp to compare the quality of some services. The results achieved were discussed during the internship held at Petrotec. As a result, the components that have the most impact on the maintenance system of the different pumps, the causes of the faults and their respective costs were identified. The most vulnerable components identified are errors in the display, heating in the engine and malfunction of electrovalves.
\end{abstract}

\section{Introduction}

The quality of the service, competitiveness, profitability and customer satisfaction depends, among other factors, on maintenance services, which have a great influence in the availability of fuel measurement systems (pumps). There is a growing discussion about the costs related to maintenance of fuel measurement system types and models, to be used at a filling The aim of this study is to propose a methodology for identifying the reliability of components and selecting the types and models of pumps to be used at filling stations and when to replace them. In order to achieve the general objective, the following aspects were considered:

i. Identify and analyse different models of measurement systems;

ii. Assessment of the reliability of the components of the different measurement systems.

The fuel measurement system is the physical structure where fuel supply occurs (Petrol, Diesel) for cars, motorcycles and others. It consists of general structure composed of measuring systems (pumps) and their pistols, element that covers the structure, platibanda, which surrounds the structure.

SNLD has in operation in its network of PA's 2104 fuel measurement systems, totalling 11984 hoses. The number of base PA's (definitive construction) is 324 and 80 containerized posts (PAC).

The data observed until 2019 in the fuel distribution and marketing segment were limited to Sonangalp, with 16 PA's and 28 CAP, and Pumamgol with 77 PA's (Fig. 1).

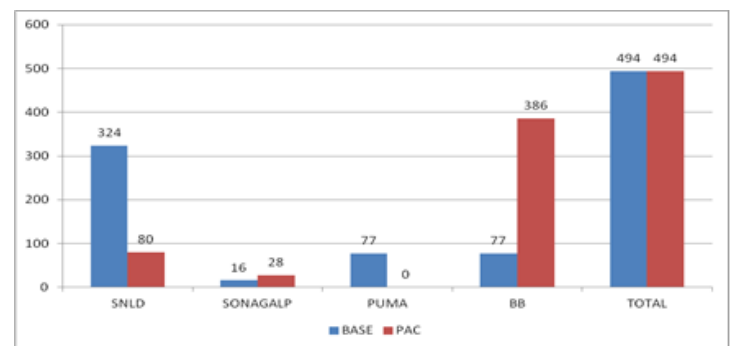

Figure 1. Number of measurement systems by operator. (By author, 2019).

In the market, there are also the Bandeira Branca (BB), which premake 77 base posts and 386 PAC's. The BB PA's has supply contracts with the distribution companies, being with SNLD, 77 PA's BB base and 386 PACs. Sonangalp, have 28 PAC's supply contracts, (DPM, SNLD. 2014).

The network of filling stations until the independence of the country was all composed of fuel measurement systems from "Tokheim". In 1995, the brand "Nuevo Pignone" was installed in two PA's. The fuel measurement systems used were manual and mechanical. The mechanical systems have been extended to electronic calculators.

In the period 1975-1996, the SNLD supply station network used pumps indicated in Table 1.

Table 1. Measuring System Types and models 1975-1996

\begin{tabular}{|c|c|}
\hline Measuring System Type & Model \\
\hline \multirow{3}{*}{ Tokheim } & 952 \\
\cline { 2 - 2 } & 1052 \\
\cline { 2 - 2 } & 1250 \\
\hline
\end{tabular}


In the period 1997-1999, the SNLD supply station network used pumps indicated in Table 2.

Table 2. Measuring System Types and models1997-1999

\begin{tabular}{|c|c|}
\hline Measuring System Type & Model \\
\hline \multirow{3}{*}{ Tokheim } & $\begin{array}{l}\text { Quantium } 210 \\
\text { Mechanical Calculator, } 2 \\
\text { Fuelguns,Qmax=40I/min }\end{array}$ \\
\hline & $\begin{array}{l}\text { Quantium 200T } \\
\text { Mechanical Calculator, } 2 \\
\text { Fuelguns,Qmax=40I/min }\end{array}$ \\
\hline & $\begin{array}{l}\text { Quantium } 510 \\
3 \text { products, } 6 \text { fuelguns, Qmax }=80 \mathrm{I} / \mathrm{min}\end{array}$ \\
\hline \multirow{3}{*}{ Euro } & $\begin{array}{l}1000 \\
\text { Simple, } 1 \text { Product, Qmax=40-130 } / / \mathrm{min}\end{array}$ \\
\hline & $\begin{array}{l}2000 \\
1 \text { Fuelgun, electronic Calculator } \\
\text { Qmax=80 I/min }\end{array}$ \\
\hline & $\begin{array}{l}5000 \\
\text { Up to } 4 \text { Products and } 8 \text { hoses, } \\
\text { Electronic Calculator, Qmax }=10-130 \\
1 / \mathrm{min}\end{array}$ \\
\hline Nuevo Pignone & \\
\hline
\end{tabular}

In the period 2010-2018, Sonangol Distribuidora's supply station network used the pumps indicated in Table 3.

Table 3. Measuring System Types and models2010-2018

\begin{tabular}{|l|l|}
\hline \multicolumn{1}{|c|}{ Measuring system Type } & \multicolumn{1}{c|}{ Model } \\
\hline Tokheim & $210-510$ \\
\hline Gilbarco & $\begin{array}{l}\text { 6 Fuelguns, 3 Products, Qmax=40-80 } \\
1 / \text { min }\end{array}$ \\
\hline & $\begin{array}{l}6 \text { Fuelguns, 3 Products, Qmax=40-80 } \\
1 / \text { min }\end{array}$ \\
\hline DresserWayne & \\
\hline Euro & \\
\hline
\end{tabular}

Other gas companies on the market use Dresserwayne, Euro and Tokheim brand pumps. Small dealers use Tokheim-branded pumps mostly with mechanical and electronic characteristics. Fuel measurement systems, in general, have the same constitution and operation as they are summarized in the Table 4.

Table 4. Measuring System Components

\begin{tabular}{|l|l|}
\hline \multirow{4}{*}{ Fuel Measuring System } & \multicolumn{1}{c|}{ Components } \\
\cline { 2 - 2 } & Calculator \\
\cline { 2 - 2 } & Meter \\
\cline { 2 - 2 } & Generator \\
\cline { 2 - 2 } & Impulse Generator \\
\cline { 2 - 2 } & Motor \\
\cline { 2 - 2 } & Aspiration System \\
\hline & Electrovalves \\
\hline
\end{tabular}

\section{Development}

For this paper, we considered tools of quality to support the diagnosis, as being:

i. Brainstorming for the preparation of the survey of the main breakdowns of the different types of measurement systems used by SNLD from 1975 to 2018;

ii. Registration of malfunctions in the maintenance department of The DPM of SNLD;

iii. Information and recognition of the different fuel measurement systems used by SNLD in the period 1975-2018.

Ishikawa diagram or cause-effect diagram, which allowed brainstorming sessions with multidisciplinary, teams. The main malfunctions and problems of the measurement systems are presented in Figure 2.

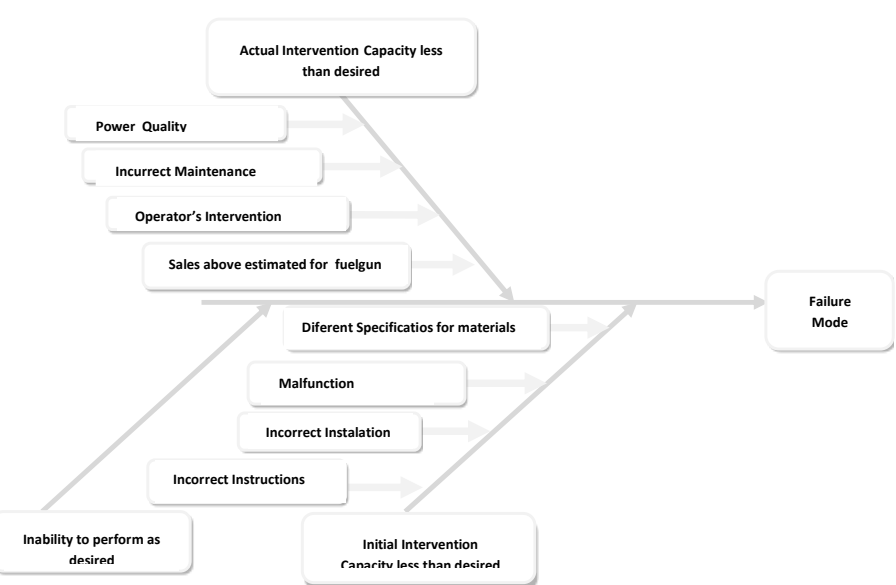

Figure 2. Ishikawa Diagram for measuring system failure mode (By author, 2019).

From the information provided and the benchmarking carried out, were identified the major malfunctions in the area of hydraulics, electrical / electronics, and motors (DPM, SNLD. 2014).

The study of the operation of given equipment or component and its behaviour with regard to breakdowns in a given period of time shall be carried out on the basis of statistical techniques and probability calculation, which are therefore subjects of no need for maintenance studies (Pinto, Carlos Varela. 2002).

Availability is defined as the probability that a component that has undergone maintenance performs its function satisfactorily for a t-time. In practice, it is expressed by the percentage of time, in which the system is operating, for components that operate continuously. For backup components, it is the probability of success in the operation of the system when demanded (Lafraia, João Ricardo Baruso. 2014).

Analysed aspects of statistical control of quality, having given particular attention to the Weibull distribution, the analysis of Variance (ANOVA), computational tools of probability and statistics, as well as descriptive statistics applied to management.

One of the objectives of the ANOVA application is to perform statistical testing to verify if there is a difference between distribution of a measure between three or more groups (Montgomery, Douglas C. 2016).

W. Weibull originally proposed the Weibull probability distribution in 1954 in studies related to failure time due to metal fatigue. It is often used to describe the lifetime of industrial products (Amaral, 2016).

The Weibull distribution is described by:

$$
F(x ; \beta ; \alpha)=1-e^{-\left(\frac{x}{\alpha}\right)^{\beta}}
$$

Where:

$$
\begin{aligned}
& \text { i. } \quad \beta \text { : shape parameter; } \\
& \text { ii. } \alpha \text { : scale parameter; } \\
& \text { iii. } \chi \text { : position parameter. }
\end{aligned}
$$

The parameter $\beta$ influence the Weibull distribution as follows:

For $0<\beta \leq 1$ :

i. $f(t) \rightarrow \infty$ when $t \rightarrow 0$

For $\beta>1$

$\mathrm{f}(\mathrm{t}) \rightarrow 0$ when $t \rightarrow \infty$;

i. $f(t)=0$ when $t=0$;

ii. $f(t)$ grows when $t \rightarrow t$ (mode) and decreases soon after.

The shape factor $\beta$ (indicates the shape of the curve and the characteristic of the failures):

i. $\quad \beta<1$ Infant mortality;

ii. $\beta=1$ Random failures (negative exponential function, infant mortality;

iii. $\beta>1$ Wear failures.

With regard to the form factor $\beta$, we have to consider: 
If $\beta=1$ (constant failure rate), may be an indication of which multiple failure modes are present or that the data collected from the times to fail are suspicious.

To analyse reliability, the different fuel measurement systems (pumps), used by SNLD from 1975 to 2018, were considered the most frequent breakdowns obtained from the proposed investigation of the analysis of existing problems and non-operating hours (down hours) of each fuel measurement system (DPM, SNLD. 2014).

All data were grouped for the 16 (sixteen) components of the 12 (twelve) fuel measurement systems, namely engines, battery error, pistol, suction group, fuses, transformer, lack of communication, engine heating, pressure gauge, electrovalvula failure, hose, totalizer and other malfunctions.

\section{Results and Discussion}

Using the concepts of planning of experiments, could confirm the reliability results using Weibull of the components. For this purpose, systems with reliability equal to or greater than $60 \%$ were considered as a starting point. Data on breakdowns of 3 (three) referenced factors and 8 (eight) experiments were considered. Major breakdowns occur in the following areas:

i. Hydraulics - including suction group, meters, electrovalves and motors;

ii. Electrical/electronic - due to the quality of energy and battery life cycle;

iii. And motors - derived from burn by difference in intensity and earth problems;

Bellow are some graphs illustrating the failure weight of components of the

fuel measurement systems and the additional information of the systems studied. From Figure 3 is clear that the Display error (17\%), Aspiration System (15\%) and Transformer (11\%) are the more critical components

The Tokheim, Quantium 200T and 510 and EURO 2000 and 5000 fuel measurement systems showed accepted reliability parameters above $60 \%$ due to the low percentage of breakdowns.

\section{Tokheim Quantium}

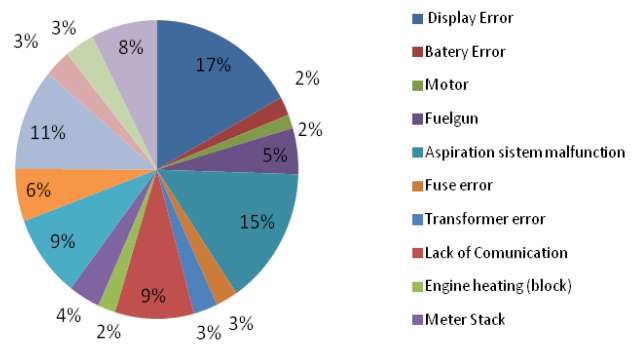

Figure 3. TQ failure breakdown

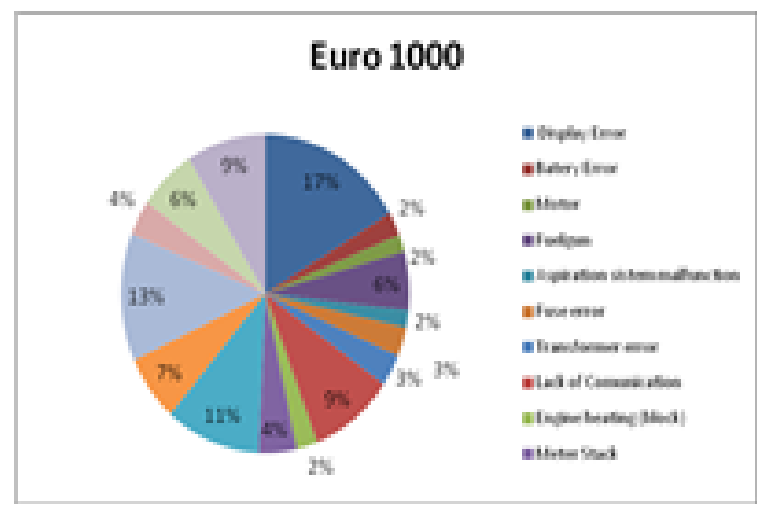

Figure 4. E1000 Failure Breakdown
Regression analysis was carried out in order to confirm the reliability of the data. This allowed evaluating the quality of the samples and incorporating them into cohesion groups.

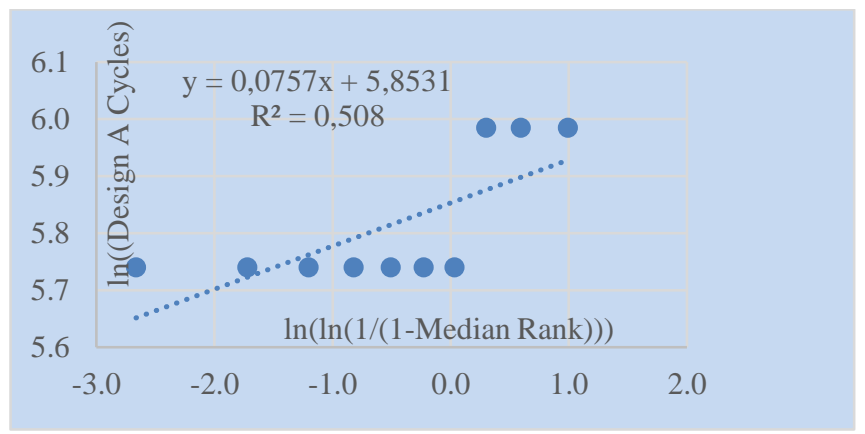

Figure 5. Meter Regression analysis

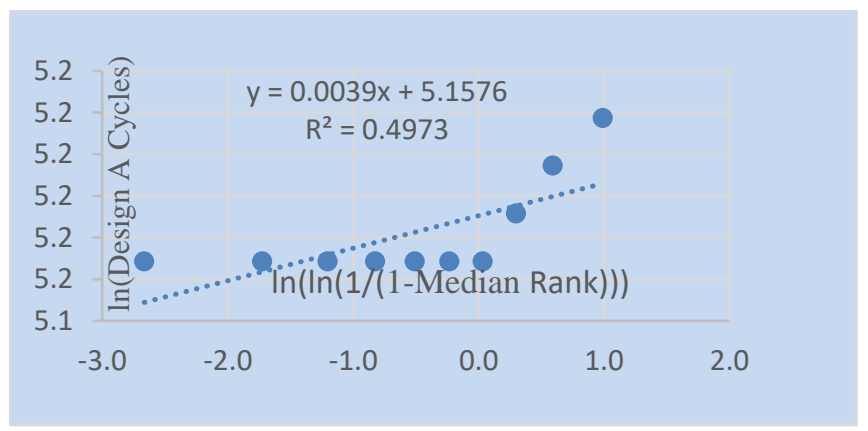

Figure 6. Motor Regression analysis

\section{Conclusions}

The reduction of the traditional maintenance structure, for a contract and service management structure, suggests the conversion of maintenance workers, whose services are performed in full by service providers. Similarly, reducing the number of types and models of systems reduces the number of service providers; the selection of types and models of fuel measurement systems for filling stations should represent one of the major concerns in the profitability of filling stations and consequent satisfaction of their customers and employees.

During the data collection for this work, 12 different types of fuel measurement systems were used in the period 1975-1996.

A better systematization of the registration of malfunctions and constant in a database allows becoming aware of all the information available in the country, although this maintenance service is mostly tercerized.

The existing information on the faults, not systematised in order to make a correlation of litters sold for each fuel measurement system and its registered breakdowns, in the 12 (twelve) varieties of systems and by each maintenance service provider in a given period.

It is suggested to optimize the measurement systems, using the Tokheim Quantium 200T and 510 and Euro 2000 and Euro 5000 systems in the PA's;

It is found that the main malfunction in the measurement systems occur so mainly on hydraulics (Suction Group, Meters, Electrovalves and Motors), as well as Electrical/Electronic (Energy Quality and Batéria/Batéria Change).

\section{Recommendations}

Following the conclusions, it is recommended to:

i. Implementation of a maintenance policy for fuel measurement systems, focused on reliability. This process can increase and efficiency of maintenance and that analyses whether, and when, maintenance is technically feasible, as well as its effectiveness (costbenefit);

ii. Adopt the methodology for selecting the types and models of fuel measurement systems, the components of which are reliable, from $60 \%$; 
iii. That in the construction, rehabilitation and change of filling station measurement systems, the proposed pumps, namely the Tokheim Quantum 200T and 510 and Euro 2000 and Euro 5000;

iv. The suggested measurement systems can also be used to assess the profitability of PA's with different characteristics and throughout the country, which have entered the object of this work;

v. Register of breakdowns in a systematized manner where there is a correlation of litres sold by each fuel measurement system and its registered breakdowns, in the different varieties of systems and by each maintenance service provider in a given period of time throughout the country;

vi. Carrying out preventive maintenance as systemic at filling stations, in order to detect possible failures in fuel measurement systems;

vii. On the other hand, and considering that man plays a fundamental role in the operationally of filling stations, and according to the benchmarking carried out, the mechanisms of motivation of workers assigned to the maintenance function should be improved by adopting an HR policy, which considers the constant formation of man taking into account the dynamics of industry;

viii. Application of the risk analysis map in the replacement of any fuel measurement system in all filling stations throughout the country, thus safeguarding the protection of the environment.

\section{Nomenclature}

DPM - Direção de Programação e Manutenção

SNLD - Sonangol Distribuidora

PAC - Posto de Abastecimento Contentorizado

PA - Posto de Abastecimento

BB - Bandeira Branca

\section{Conflict of interest}

The author declares that there is no conflict of interest regarding the publication of this manuscript.

\section{References}

Amaral, Fernando Dias. 2016. Gestão da Manutenção na Indústria.[Online]. Fonte: http://www.bertolo.pro.br. 2018.

Cruz, Carlos Perreira. Gestão Ambiental, Sintonizar Ambiente e Estratégia para o Negócio. 2009.

DPM, SNLD. Registo de manutenção de Bombas. 2014

GILBARCO. [Online] 2019. Retirado de https://www.gilbarco.com/produtosbombas. 2019.

ISO 9001: Guia Práctico. 2015.

Lafraia, João Ricardo Baruso. Manutenção de Confiabilidade, Mantenabilidade e Disponibilidade. 2014.

Lock, Lock Patti, Morgan, Lock Eric \& Lock Dennis.. Estatistica Revelando o Poder dos Dados. 2017

Magalhães, Oliveira \& Silva. Estatistica Descritiva aplicada à Gestão. 2017.

Montgomery, Douglas C. Introdução ao Controle Estatistico da Qualidade. 2016.

Montgomery, Runger \&Hubele. Estatistica Aplicada à Engenharia. 2004. 